\title{
Conceptualizing television news interpretation by its viewers: The concept of interpretive complexity
}

\author{
GABI SCHAAP, KARSTEN RENCKSTORF and FRED WESTER
}

\section{Abstract}

In recent years many scholars seem to agree that viewers' interpretations play a prominent role in the influence of television news. However, a clear concept of 'interpretation' is still missing. This article proposes to conceptualize interpretation as the 'representation' of a news item as constructed and reported by a news viewer. More specifically, we look at this representation in terms of its complexity. Two aspects are important: first, the fundamental elements viewers use in their interpretation (differentiation), and second, how the viewer relates these elements to one another on a more abstract level (integration). Together, differentiation and integration represent the complexity of the viewer's interpretation of a television news item. The article provides definitions of these concepts and argues that interpretive complexity can be useful in studying the influence of television news. It concludes by outlining research questions in the field of television news using interpretive complexity.

Keywords: television news use, interpretation, user perspective, interpretive complexity, differentiation, integration

What impact does television news have on its viewers? Although relatively little is known about the answer to this question, among the things that many communication researchers seem to have agreed upon in recent years is that the influence of television news is something in which meaning construction by the viewers plays a prominent role. Watching news is 'making meaning'. This is a much more complex process than merely absorbing and reproducing news facts. To make sense of a news item, viewers restructure it in their minds, elaborate or simplify it, and integrate parts of it into their stock of knowledge, while other parts are seemingly discarded. Because of this, neither the reception nor the im- 
pact of television news can be satisfactorily measured by testing the recall of news facts, which has been the standard way of studying the impact of news (Al-Menayes and Sun, 1993; Berry, 1983; Graber, 1984; Höijer, 1998; Neuman, 1981; Putnam, 1971; Schaap, 2004; Woodall, Davison, and Sahin, 1983). In other words, to answer the question on whether and how the news affects its viewers, one must ask the question what meanings viewers construct from this complex combination of sounds and images (cf. Findahl, 1998, 2001; Gunter, 2001; Höijer, 1989, 1998; Höijer and Werner, 1998; Jensen, 1998; Robinson and Davis, 1990; Renckstorf and Wester, 2001; Shapiro and Lang, 1991).

Unfortunately, what is exactly meant by 'meaning' has often remained somewhat opaque. As a consequence, measuring how people interpret the news has been problematic, and little is still known about the meanings audiences (re)construct from a news broadcast (Gunter, 2001; Schaap, Renckstorf, and Wester, 2001). Here, we use an approach that tries to be sensitive to the complex reconstructive nature of dealing with television news - which we will call the 'interpretation' of the news by taking a 'user perspective'. This perspective looks at the interpretation of the news from the standpoint of the viewer, and places what is meaningful to the viewer at the center of its attention as opposed to what is necessarily meaningful or 'correct' to the researcher or journalist.

In sum, in order to study how television news affects its viewers, it is relevant to study how viewers interpret the news. And in order to be able to study interpretation, we need to conceptualize it. How to assess viewers' representations of the news is addressed elsewhere (Schaap, 2004). Here, we propose that the interpretation of a television news item can be seen as a representation of the news made by a viewer. Depending on viewer characteristics, news features, and the viewing context, representations can vary in terms of the amount of elements and relations between the elements that are used.

With these two dimensions of what we call 'interpretive complexity' we will focus on the structure rather than on the content of interpretations. This means one can discriminate between people's interpretations without having to resort to evaluating what the viewer has precisely 'meant' in the interpretation. Assessing what an interpretation means is highly subjective; it is easier to attain some level of 'objectivity' in recognizing how interpretations are structured than it is in assessing whether elements are 'correctly' used, or what the 'true' meaning of an interpretation is (cf. Luskin, 1990; Neuman, 1981; Schaap, 2004; Schroder, Driver, and Streufert, 1967; Tetlock, 1984). Therefore, interpretive complexity is more in line with a 'user perspective'. Simultaneously, we hope to develop a concept that allows us to measure inter- 
pretation in a more systematic way. This article discusses the consequences of using the concept of complexity for the study of television news interpretation and news impact in our concluding paragraph.

\section{Interpreting the news}

To interpret television news, viewers use their knowledge about facts, people, motives, norms, values, action strategies, as well as knowledge about, for example, what news is, what one can expect from the news, and how to watch it (cf. Lemish, 2004). They have acquired this knowledge throughout their lives through personal experiences and socialization. This idea is not new; similar views have existed for decades in a wide range of disciplines such as cognitive and social psychology, sociology, anthropology, and linguistics, although each discipline employs its own specific terminology (e.g., Berger and Luckmann, 1967; Fisher, 1997; Fiske and Taylor, 1991; Goffman, 1974; Graesser, Singer, and Trabasso, 1994; Kintsch, 1998; Parkin, 2000; Putnam, 1971; Spradley, 1972; Vitouch and Tichon, 1996). In this view, watching television news can be seen as a 'meeting' of a viewer with the content of a news program in a certain social context, during which the viewer constructs a meaning from the news (cf. Wahldahl, 1998). The viewer brings to the meeting his or her individual and social characteristics: a personal life history, experiences, interests, goals, attitudes, and membership of various social groups, all stored in knowledge. The news also brings its characteristics to the meeting; not only the topics on which it reports - its 'content' but also formal features such as sounds and images, the structure of an item, or its length. Both news content and audience characteristics may determine the eventual 'meaning' of a news item. A news item that strongly resonates with what a viewer knows, feels, and is interested in will, for instance, be interpreted differently than an item for which this is less the case. Finally, the social context in which the news is presented and watched is of importance. For instance, major social or economic events and circumstances, or perceived public opinion can have a strong impact on how a viewer interprets the news. Thus, a news item on the price of Enron shares may take on different meanings for viewers before and after the financial scandal. In other words, interpreting the news is a dynamic process; meanings change as knowledge changes in a changing environment (Findahl, 1998; cf. Livingstone, 1990). The result of this meeting, and of the process of interpreting the news, is the representation of the news item that is constructed by the viewer.

An example is the study we are currently conducting in which viewers reported their thoughts on a television news item dealing with agricultural reforms and their consequences for meat consumption. Two of the 
respondents held opposing views; one stated s/he found the item interesting, while the other found it not at all interesting. The first viewer reported thinking about, among other things, "life on a farm, with chickens and pigs", the "things such as the hormones that farmers add to animal food", and "genetically modified starch", the consequences of this for public health, such as "getting a hole in your brain", as well as the fact that "consumers do not want to pay too much for their groceries". The second viewer had much fewer thoughts; they focused on the fact that the viewer's "brother-in-law has a cow farm as well", and that the "reporter is a well-known foreign correspondent".

This example serves to illustrate the premise that the interpretation of a television news item has at least three structural characteristics. First, an interpretation can be seen as a collection of individual components. For the first viewer these are, for instance, a farm, farmers, chickens and pigs, genetically modified starch, public health, consumers, and groceries. Some of the components of this viewer's interpretation come from the news item itself, such as the consumers and their not wanting to pay too much. Others, while inspired by it, do not come directly from the news item, for instance, the modification of food and its dangers to public health. A second characteristic is that some of these components are connected; the first viewer directly connects (the eating of) food with added hormones to "getting a hole in your brain", i. e., one is the result of the other. Finally, one can group these components into different 'topics', or categories; some components, such as farm life, pigs, and chickens are all related to the same 'area' one can refer to as 'agriculture', whereas others seem to represent categories dealing with 'health' and 'economy'. Thus, in this conceptualization one sees news interpretation as a representation of a news item that is made up of elements and connections between elements and which can be seen as being part of different categories (cf. Renckstorf and Wester, 2001; Roskos-Ewoldsen, 2004). Together, these are the characteristics that form a specific individual representation of a news item as constructed by a viewer.

More can be learned from this example. There are differences between the interpretations of these two viewers, as the second viewer's reconstruction included different components, from different areas (one could call them 'family', and 'journalism'), and no direct connections of any kind. In other words, the two interpretations are structured quite differently. We suspect that viewers with different relevant characteristics (in this particular case this may be differences in interest) are prone to have differently structured interpretations.

Below, we will elaborate on how interpretation is influenced by knowledge structures, and adopt concepts from disciplines that are concerned with the study of knowledge structures to our concept of interpretation. 


\section{The structure of interpretation: Interpretive complexity}

The fact that a viewer's interpretation of a news item has a certain structure that may differ from another viewer's interpretation is because the knowledge the viewer uses to interpret a news item is structured in a specific way that most likely differs from person to person. In other words, interpretation is a direct product of the use of knowledge ${ }^{1}$. A person's stock of knowledge consists of separate yet interlinked elements which are divided into categories and subcategories in a system that increases in complexity as the number of categories and subcategories increases. How knowledge is structured and how it is used in mental processes differs from person to person and from situation to situation. As a consequence, the products of these different mental structures and processes will vary as well (Segal and Shaw, 1988). One of the primary products of these processes is a personal representation of the news item. As different viewers have different knowledge structures, the structure of their interpretations will differ as well. Here, we will not focus directly on mental processes, as they are only of indirect concern to communication scholars and are more suited as object of study for psychologists. However, interpretation as a product of these processes is of great importance to the study of the influence of television news.

Ultimately, it is important that one can compare interpretations with different structures. Therefore, it is important to assess in what way the structure of interpretations can vary. In the description of knowledge structures, one can see the similarities with the characteristics of interpretation; both consist of elements that are linked in one way or another. Therefore, in order to assess how the structure of the interpretation can differ between viewers, we will adapt a concept that has been used in other scientific disciplines to describe these characteristics of knowledge, called cognitive complexity ${ }^{2}$. Complexity refers to the amount of elements and the level of coherence or connectedness between the elements, called 'differentiation' and 'integration', respectively. Accordingly, the interpretation of a news item can also be highly differentiated if viewers incorporate many elements, and highly integrated if viewers make many connections between elements. A highly differentiated and integrated interpretation of a news item suggests an interpretation that contains fine distinctions, flexibility in attitudes and beliefs, and extensive information use, whereas a less complex interpretation suggests gross distinctions, rigidity, and restricted information use (Hinze, Doster, and Joe, 1997; Schroder et al., 1967; Putnam, 1971; Suedfeld and Tetlock, 1977). In order to distinguish between the concept of cognitive complexity (i. e., the complexity of knowledge systems) and what we do here, we will call the complexity of the interpretation of a news item 
'interpretive complexity'. Below, we will discuss the two aspects differentiation and integration in more detail.

The complexity of the interpretation of a news item is largely domainspecific, that is, a person does not necessarily have a complex interpretation of the world in general, but rather of a specific knowledge domain (Suedfeld, Tetlock, and Streufert, 1992; Tajfel, 1981; Tetlock, 1984). This means that the same viewer can have a highly differentiated and integrated interpretation of a news item on the latest Star Wars movie and a much less differentiated and integrated one of a news item on the political situation in the Middle East. Conversely, the same news item may result in differences in interpretive complexity among different viewers as their personal circumstances are different. As shown, knowledge, personal experiences, interests, and the social situation of a viewer have consequences for the way he or she interprets a news item. So a science fiction fan may have a complex interpretation of the Star Wars item, whereas the interpretation of the same item by a professor in Middle Eastern politics may be markedly 'simpler'. In the concluding paragraph I will discuss in short how these relations can be used to test hypotheses on the influence of the news.

\section{Interpretive differentiation: Number and range of elements}

As seen, the interpretation of a news item consists of certain basic units or building blocks that together make up the viewer's representation of the news. Such elements may include people, for instance, 'a farmer', or 'consumers', acts performed by these people, such as 'adding hormones to food', or 'buying', objects like 'animal food', and attributes of these things like 'the price of meat', as well as reasons for, or consequences of acts. Differentiation is the degree to which a viewer uses such elements in the interpretation. As we will see, differentiation refers to both the number of distinct elements and the range, or the types of elements used in an interpretation. Accordingly, a person's interpretation of a news item can be called more differentiated as the number and range of elements in the interpretation increases (Linville, 1982; Luskin, 1987; Neuman, 1981; Schroder et al., 1967; Scott, 1963; Suedfeld and Tetlock, 1977; Tetlock, 1984).

But what should be regarded as elements? To answer this question, we turned to the ethnologist Spradley, who is interested in the elements members of a culture use to give meaning to the social situations they encounter in everyday life (Spradley, 1972, 1979, 1980; Spradley and McCurdy, 1972). All these elements combined make up the basic layout of a social situation as perceived by its participants. Important to this study is that Spradley describes a list of general types of all the possible 


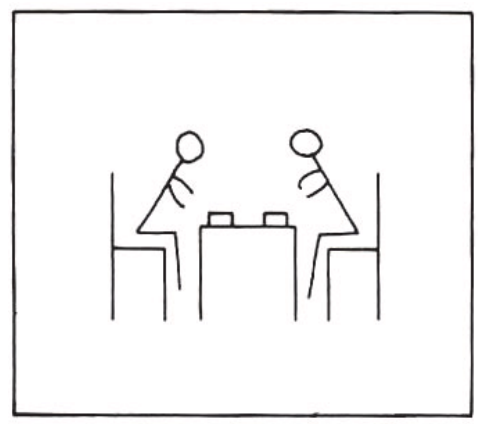

Figure 1. A social situation (Source: Spradley, 1980: 87).

elements which can be applied to any situation. People do not use these general types, they are merely categories constructed by a researcher in trying to discover systematic features of interpretations. People do use specific elements in their interpretation; each of these specific elements can be classified as one of the general types. To illustrate and clarify this, consider Figure 1, which is taken directly from Spradley. It represents some undefined social situation, in which two people sit at a table with some objects on it, which are manipulated from time to time.

Now, depending on the specific social situation, the general elements of this situation - people, objects, handling of objects - represent different specific people, objects, and actions. If Figure 1 represents a chess game, the specific actors, objects, and actions are different than if the illustration depicts a political debate, lunch hour, or two students in a library. In the same way, viewers of television news interpret the news using specific instances of these general elements. Thus, the general types of elements that are used in interpreting a social situation are the same as the elements that can be used in the interpretation of what may also be called a social situation; watching a television news item.

Spradley's list of general categories of elements is based on two premises (Spradley, 1972). First, the elements for giving meaning to any social situation correspond to the basic components of any given social situation. A(n) (ideal) social situation consists of actors with certain goals and feelings, who are engaged in an activity that consists of single actions, that is embedded in a set of related activities called an event; all this takes place in a specific space which contains objects, and during a certain period of time (Spradley, 1979, 1980). For instance, two chess masters, both with the goal to win and feeling a bit tense, are engaged in a chess game where they think and move pieces, during a chess tournament. This takes place over a period of three days in the tournament hall, which contains tables and chairs, chess pieces and boards. Thus, a 
Table 1. Elements in the interpretation of a television news item: Some general elements and examples.

\begin{tabular}{ll}
\hline General categories of elements & Examples of specific elements \\
\hline $\begin{array}{l}\text { Inclusion: } \\
\text { Kinds of... }\end{array}$ & \\
Actors & Albert Einstein is a kind of actor \\
Acts & To think is a kind of act \\
Activities & Debating is a kind of activity \\
Events & A debate is a kind of event \\
Goals & Solving a problem is a kind of goal \\
Feelings & Self-confidence is a kind of feeling \\
Objects & A desk is a kind of object \\
Space & A TV studio is a kind of space \\
Time & Today is a kind of time \\
Attribution: & \\
Attributes of ... & \\
Actors & Intelligence is an attribute of Albert Einstein \\
Objects & A brown color is an attribute of a desk \\
Cause-effect: & \\
Results of ... & \\
Acts & Solving the puzzle is a result of thinking \\
Events & Feeling frightened is a result of a loud bang \\
Rationale: &
\end{tabular}

first clue to what elements in the interpretation of a social situation are is that they concern the components actors, goals and feelings, activities, acts and events, and space, time, and objects.

Second, when people give meaning to a situation they always somehow link these components on a very basic level. Called 'semantic relationships', these links relate specific components to small categories. The number of various types of links is limited ${ }^{3}$. In his research Spradley has successfully used nine types of links: inclusion (kinds of things), attribution (attributes of things), spatial (parts of things), location-for-action (places for things), sequence (the steps of phases in/of things), causeeffect, functions (the functions of things), means-end (ways to achieve things), and rationale (reasons for things) (Spradley, 1980: 93).

Combining the two dimensions 'components of social situations' and 'semantic relationships' creates a matrix, in which one dimension represents the general components of social situations, and the other dimension represents the semantic relationships, defining all possible types of 
elements that can be part of the interpretation of a situation (cf. Spradley, 1980: 82-83). These types of elements are for instance (using the semantic relationship 'inclusion'): kinds of actors, kinds of acts, kinds of activities and events, kinds of objects, kinds of goals and feelings, and kinds of space and time; or (using the semantic relationship 'attribution'): attributes of actors, acts, and activities, etc.; or (using 'rationale'): reasons for activities, feelings; or (in 'function'): functions of acts, objects, etc. Table 1 lists some of the general categories and provides examples of specific elements in these categories. Thus, the representation of a news item constructed by a viewer consists of various kinds of people with specific characteristics, the things they do, the reasons they have for doing things, or feeling the way they feel, the objects they use, the effects acts and feelings have, etc. The fact that this conceptualization of differentiation includes all elements that can possibly be included in an interpretation makes it highly useful for our purposes.

Now that we have established which elements the concept of differentiation refers to, one can distinguish between two types of differentiation. One viewer's interpretation of a news item may consist of, for instance, several actors, such as Jacques Chirac, Gerhard Schröder, and George W. Bush. A second interpretation by another viewer may consist of one actor, George W. Bush, and in addition an act, e.g., voting, and an object, e. g., an amendment. The amount of elements both viewers used is the same; three. However the range of elements is different. The first viewer uses three elements of the same type, namely all actors (even more specific, they are all politicians). The second viewer uses three elements of three different types: an actor, an act, and an object. Therefore, although the number of elements used by both viewers is equal, the range of elements is different. Both characteristics of differentiation are important; they represent the degree to which a viewer's interpretation is specific and heterogeneous.

In sum, interpretive differentiation can be understood as the number and range of distinct basic elements as described above. Thus, the interpretation of a television news item consists of specific discriminate elements which can be used to distinguish general 'kinds' of actors, acts, activities, events, objects, feelings, goals, times and places, and their 'attributes', 'causes and consequences', 'reasons', 'phases', 'places to do things', and 'ways to achieve things'.

\section{Interpretive integration: Relationships and domains}

The structure of interpretation is characterized not only by the use of separate elements, but also by the way in which viewers link these elements. Whereas elements are almost always connected on a basic level 
in semantic relationships, as can be seen above, integration refers to a form of association at a higher level of abstraction ${ }^{4}$. A person may use many elements, for instance, kinds of actors, but fail to connect them in any meaningful way. So, such a person's interpretation may be highly differentiated yet at the same time it lacks coherence. Such a representation of a news item would be less structured, or less 'complex' than a representation in which elements are connected. In sum, the greater the amount of such connections between elements, the more highly integrated the interpretation is. From the above we can gather that differentiation is a necessary but not sufficient prerequisite for integration, because people using a greater number of actors, acts, and so forth in their interpretation have more opportunities to link elements than people who use a smaller number of elements (cf. Guttieri, Wallace, and Suedfeld, 1995; Neuman, 1981; Schroder et al., 1967; Tetlock, 1984; Suedfeld et al., 1992; Tetlock, 1984; Zajonc, 1968).

There are two ways in which a person can connect elements. First, on a micro level, he or she may connect two or more individual elements. Second, on a macro level, many individual elements are implicitly connected by grouping them in coherent structures, or socio-cultural categories called domains (cf. Judd and Krosnick; 1989; Wahldahl, 1998). Below, we will specify these two variations of integration.

\section{Micro-integration: Relational elements}

One way in which an interpretation shows coherence is through the linking of individual elements. Although every element represents some type of relationship, one could posit that some of these relationships, and consequently some of these elements, are of a higher level of abstraction (Höijer, 1989; Luskin, 1987). These are abstract elements that contain actual explicit relationships between two or more concrete elements. Different kinds of people, places, and events are concrete, observable components of a news item, whereas for instance causes and consequences are more abstract, not directly observable in nature (cf. Al-Menayes and Sun, 1993; Findahl and Höijer, 1985; Schroder et al., 1967). Expanding on this definition, we define elements that contribute to micro-integration as elements referring to explicit relations in terms of direction, logic, or time. Some of the elements that we adopted from Spradley belong to this category; they are the elements concerning cause-effect relations (directional relations), rationale and function (logical relations), and sequence (temporal relations).

In short, a first aspect of the coherence or integration of interpretation can be defined as the occurrence of an explicit relationship between at least two individual elements in terms of logic, time, or direction. The 
more such explicit relations an interpretation contains, the higher its 'micro-integration' is. Thus, in addition to differentiation, a second aspect of interpretation of a television news item is called 'micro-integration'.

\section{Macro-integration: Domains of elements}

On a still higher level of abstraction, a second type of coherence in news interpretation is the grouping of elements into larger coherent structures, or categories. Although our definition differs somewhat from Spradley's, we will use his term and call these categories 'domains'. In interpreting the news, a viewer may use domains regarding for instance 'politics', 'healthcare', or 'private life'. When a viewer uses, say, five domains in the interpretation of a news item, this viewer in fact links these categories to each other and to the news item. In other words, such a viewer integrates these domains into his or her representation of the news item, and does this to a larger degree than a viewer who uses only one or two domains in a representation of a news item. In other words, the latter interpretation is less integrated than the former.

A domain is a category in which aspects of reality are grouped that belong to the same social sphere; i. e., it defines what belongs to a social sphere and what does not. Domains are social products; that is, they are defined by shared meanings. Over time, within and sometimes even across social groups, people have developed shared ideas on what actions, events, etc. mean or should mean, what they represent, and how they relate to each other. Elements that share a common ground, on which there is some consensus on a common meaning, belong to the same domain. In other words, people agree on the general content of social areas, and share a general 'definition of the situation'. At the same time, they share definitions of the boundaries of an area, of what is and what is not included (cf. Rosengren, 1986) ${ }^{5}$. In our concept, this means that a domain consists of all elements, such as actors, acts, events, and objects that are related to the same social sphere, such as 'the economy', or 'private life'.

We can get a sense of which domains can be used in the interpretation of the news because the way society has been organized originates from shared meanings. Domains make standard interpretations readily available to the individual, thus facilitating the process through which people make sense of the world. Therefore, the way in which we organize society is reflected in the domains we use when giving meaning to the world, and vice versa. Some of these domains in society are in fact organized in a literal, professional sense; they are 'institutionalized'. They are routine solutions to recurring interpretation problems made 'official', laid down 
in 'objective', established rules and regulations for action, sometimes literally set in stone (Berger and Luckmann, 1972). So, many political institutions are institutionalized domains. The department of 'education' relates to the social-cultural sphere in which all actors in the area of education (teachers, students, school boards) engage in social activities related to the area (teaching, studying, making a curriculum), in designated places (schools, class rooms), using objects (blackboards, books, other study materials). Likewise, 'economy', 'defense', or 'justice', are domains with their own specific elements, many of which are unique to the domain. In a similar fashion, news media, as important potential 'defining powers' in western societies, organize world events by placing events into specific news sections in the newspaper, or specialized news programs, such as economy, sports, science, showbusiness, foreign news, media, and advertisements. These institutionalized domains are of particular interest for studying the interpretation of the news, as we can expect that many of them are used by news makers in making, and by viewers in interpreting a news item (cf. Graber, 1984; Jensen, 1998; Luskin, 1990).

However, individuals do not share all their situation definitions all the time with everybody, just as individuals do not share their personal history and social background with every other individual. Therefore, in some cases a viewer will define a situation utilizing his or her own idiosyncratic definitions, using domains that are not shared by many other people, and are not used in the news item. In other words, viewers are not only domain users, but also domain makers. Some domains may only be meaningful to that particular person or a very small group of people. Predicting the idiosyncratic domains that will be used in the representation of a news item is much more difficult, which is why we can only assess them after viewers have produced their interpretation (cf. Graber, 1984; Spradley, 1980).

In sum, interpretive domains are categories of elements that are related to areas in social reality. In our concept, all actors, acts, events, objects, attributes, causes, functions, etc. that relate to one social area constitute one domain. The domain of 'agriculture', for instance, contains all agricultural people, agricultural acts, agricultural events, and their consequences, whereas the domain 'journalism' contains journalistic actors, their journalistic acts, and their consequences, etc. Macrointegration, then, is the degree to which a viewer associates domains with a news item and with other domains, and how many domains the representation of a news item incorporates. We can see how different news items on different subjects may be interpreted using different domains, and also how different viewers from different individual and social backgrounds may use different domains while interpreting the same news item. 


\section{Interpretive complexity: Two approaches to the concept}

Above, we have defined interpretive complexity or interpretive differentiation and integration as the degree to which viewers include elements, and elements of varying kinds, the relations between elements, and domains in their interpretation of a news item. Each interpretation may differ from another in the number of elements, types of elements, relationships, and domains that are included. Thus, some viewers have a more, or less, complex interpretation of a news item than others. This is a quantitative approach to the concept, where the number of elements, relationships, and domains that the viewer includes in the representation of a news item are counted and compared. Earlier we sketched how an interpretation of a television news item consists of several components. Figure 2 outlines how these components called differentiation, as well as micro- and macro-integration, all contribute to the complexity of an interpretation. As Figure 2 shows, the individual components known as elements are the elements $a-h$, one of which (element $f$ ) contains a relationship (micro-integration). All these elements can be grouped into three domains (macro-integration): agriculture, health, and economy.

A second, more qualitative approach is also possible. This approach entails looking at the nature of the elements, relationships, and domains

\section{Domain 1: Agriculture}

\begin{tabular}{l}
\hline Element a: \\
Farm \\
Element b: \\
Farmers \\
Element c: \\
Adding \\
hormones to \\
animal food \\
Element d: \\
Cow \\
\hline
\end{tabular}

\section{Domain 2: Health}

Element e:

Public health

Element f:

A hole in your

brain is a

consequence of

adding hormones

to animal food

\section{Domain 3: Economy}

Element g: consumers

Element h:

Paying for groceries

Differentiation $=($ element $a$, element $b$, element $c \ldots$ element $h)$

Micro-integration $=($ element $f)$

Macro-integration $=($ domain 1, domain 2, domain 3$)$

Figure 2. Interpretive complexity: Differentiation, micro- and macro-integration. 
in an interpretation. One viewer could use some particular elements and domains in his interpretation, whereas another viewer could use other elements and domains. For instance, in our first example, one of the viewers used the domain 'agriculture', which among other things included farmers and cows. A different viewer might also use the domain agriculture, but may include other elements, such as animal diseases and crop failure, or he or she may not use the domain agriculture altogether, and connect the item to such things as 'culture', or 'war'. So, viewers may vary not only in the number of elements, relations, and domains included in the interpretation, but also in the kinds of elements, relations, and domains. In order to understand how people make sense of the news, it is important to see what specific elements and domains are used by what kinds of people in the interpretation of a television news item (Wahldahl, 1998).

\section{Discussion}

In this article, we assumed that the influence of television news on its audience is affected by the interpretation a viewer creates of the news. Consequently, to study the influence of television news is to study the interpretation of television news by viewers. In an attempt to develop a useful concept of television news interpretation, we proposed that a viewer's interpretation of a news item can be seen as a representation of that item. This representation is a more or less complex structure of connected elements, some of which come from the news and others from the viewer's knowledge. In this view the complexity of the interpretation is characterized by two aspects: differentiation and integration. They represent the broadness and coherence of the interpretation of a television news item.

One aspect of this concept that gives it an advantage over previously used methods is that it, while giving a broader insight into what people do with the news, focuses on the structure rather than on the content. Thus, it allows us to measure and compare what different people do with the news without the need to classify their reception as 'right' or 'wrong' as recall-based studies do, or to have the researcher determine exactly what a viewer 'means'. This approach thus tries to be true to a 'viewer's perspective', in which the act of defining what is right or true in the reception of a news item is left as much as possible to the viewer instead of to the researcher. Of course, the role of the researcher, while diminished, is still crucial.

A second advantage may be that, although we are primarily interested in television news, we see no reason why this idea could not be adopted to the study of reception of other news media, or other genres, such as drama, for that matter. 


\section{Old and new research questions}

Our concept is based on the assumption that how a viewer's knowledge is organized affects the complexity of the interpretation of the news, and this in turn affects if and how the news has consequences for a viewer. How might this concept of interpretation be of use in research on the impact of news? Here, we present a far from comprehensive list of potential research questions, some old, some new (cf. Gunter, 2001; Schaap et al., 2001).

First, we know that viewer characteristics affect how people process the news. Gender, age, and socio-economic status, the viewer's previous knowledge and cognitive skills as well as interests and involvement have all been found to correlate with news recall and understanding (Brosius and Berry, 1990; Drew and Reeves, 1980; Findahl and Höijer, 1985; Giegler and Ruhrmann, 1990; Gunter, Furnham, and Gietson, 1984; Hendriks Vettehen, Hietbrink, and Renckstorf, 1996; Höijer, 1996; Lockhart and Craik, 1972; Renckstorf, 1980; Robinson and Levy, 1986). An important question is how these characteristics relate to the interpretation of the news. Which viewers interpret the news in which way? How do individual or social differences influence how and what people think about the news? For instance, people with complex cognitive structures regarding an issue - that is, with much and well-organized previous knowledge - tend to be more resilient to disconfirmation than people with 'simpler' cognitive structures. This raises the question whether people with a more complex interpretation are more prone to have a view that is more independent from the journalist's view (cf. Fiske and Taylor, 1991; Luskin, 1990; Petty and Cacioppo, 1981). A second hypothesis is that highly complex interpretations correspond with a higher level of storage, reproduction, and ultimately understanding of information (Graber, 1984; Findahl and Höijer, 1985). Thus, particular groups of viewers may be more likely to have a low level of understanding and at the same time be more subject to manipulation than other groups. In the end this may mean that longer-term attitudes and actions such as voting are influenced by the complexity of the interpretation of issues. One could hypothesize for instance that viewers who have a relatively simple interpretation of certain public affairs news are attracted to political parties that present specific social problems in simple, one-dimensional ways.

One of the most heavily studied issues in television news research is the relationship between content features and audience impact. By far, most research has concentrated on the impact of various content features on the recall and comprehension of facts. Our concept of interpretation may help to elaborate on the conclusions from these studies, not only by 
focusing on interpretation instead of recall and comprehension, but also by adopting the concept of complexity to news content. In the past, the complexity has been assessed of transcripts of meetings of high government and military leaders in the wake of crises like the Cuban missile conflict, and of speeches by world leaders (Guttieri, Wallace, and Suedfeld, 1995; Satterfield, 1998; Suedfeld and Tetlock, 1977). Analyzing the complexity of the news content gives us a new way of assessing the 'content' of a news item that makes it possible to compare different news items or news bulletins (cf. Kleinnijenhuis, 1990; Kleinnijenhuis, Peeters, Hietbrink, and Spaans, 1991). This way, we can also track the differences in the way news is presented to the public over time and test the oftenmade claim that the news has become increasingly simplified over the years.

Moreover, comparisons between the types of elements presented in the news and those used in the interpretation by viewers could test hypotheses about 'bottom-up' and 'top-down' processing (Findahl, 1998; Woodall et al., 1983). One interesting question is whether more complex news content has a positive or a negative effect on the complexity of viewers' interpretations. Does the inclusion of a cause-effect element invite viewers to use cause-effect reasoning in their interpretation? And conversely, does the exclusion of such reasoning prevent the viewer from making these connections? In addition, we could investigate whether the reception of television news is more fragmented and at a lower level compared to other media and messages, such as news papers or drama television (cf. Höijer, 1989; Iyengar, 1991; Salomon, 1984; Walma van der Molen and Van der Voort, 1997).

In a similar vein, the consequences of news content features other than complexity of interpretation can be studied. Textual characteristics such as narrative construction, the order in which items are presented, as well as the actual issue, emotional content, framing, and visual presentation features such as graphics, or text-image discrepancy are all known to affect news processing, and may very well affect the representation of a news item made by the viewer (Carragee and Roefs, 2004; Van Dijk, 1983; Graber, 1990; Gunter, 1979; Höijer, 2001; Shah, Kwak, Schmierbach, and Zubric, 2004). Some of these features may facilitate more complex interpretations, while others, such as emotional pictures, perhaps counteract complexity. In short, in this way the power of the news to define interpretations could also be looked into.

Finally, the context in which the interpretation takes place may affect how news works. The social context not only includes the direct environment of the home, others present, and the activities that co-occur with news viewing (Konig, Renckstorf, and Wester, 2001; Levy, 1978; Van der Molen, 1989). It also includes the larger social environment, including 
the perceived dominant public opinion, recent events, social crises (e. g., 'breaking news'), and more intrapersonal factors, such as personal crises, fatigue, stress, and the like (Suedfeld et al., 1992). All these factors may influence interpretive complexity. Some issues become much more prominent and urgent in the media after crisis events (e. g., 'war on terror') and after some time, these reports may change in intensity and perhaps in complexity (Findahl, 1998; Früh, 1990; Suedfeld and Leighton, 2002). Tracking if and how the interpretive complexity related to such issues changes is important to understand the long-term influence of news reporting.

Before we can begin to study these questions however, our first step should be to operationalize the proposed theoretical concept. The usability of our concept rests very much upon the assumption that it is possible to have the viewer report his or her representation of the news item. In our view, it is important to reduce the possible influences of the researcher on the interpretation as much as possible. An interpretation undisturbed by things such as predefined questions or answer categories teaches us more about how viewers interpret the news from their vantage point. One way to do this is by using qualitative interviews, in which viewers can voice their interpretation in their own way. In addition, it is important that we can measure the interpretation at the actual moment of the meeting between news content and viewer, as this is the moment when an image of a news event is created that may affect thinking later on in time (Findahl, 1997). In a pilot study we have used a ThoughtListing Technique to obtain access to news constructions. This method involved having participants provide verbal reports of these constructions during the viewing of a news program. This study and others demonstrate that the technical difficulties of eliciting such reports can be solved (cf. Schaap, 2004).

In addition to technical problems, measuring interpretations via these types of procedures poses some additional questions, most of which are typical of research into cognitive processes or meaning giving, and some of which may never be completely solved. One important question is how reports by participants relate to thoughts, reflections, and emotions that are actually experienced by a person (cf. Ericsson and Simon, 1984; Van Someren et al., 1994). Although protocols never allow us to completely measure all the thoughts people have, there are many indications that protocols are fairly representative of the actual thoughts people had (Cacioppo, Von Hippel, and Ernst, 1997; Davison, Vogel, and Coffman, 1997; Ericsson and Simon, 1984; Van Someren et al., 1994). One additional indication from our own pilot study is the fact that participants report seemingly 'irrelevant' thoughts; almost $8.5 \%$ of viewers' thoughts did not have a direct relation to news content (Schaap, 2004). Further- 
more, in contrast to studies in which cognitive processes such as problem solving are traced, the operationalization of our concept does not have to be based on the assumption that the reported thoughts represent actual literal thoughts (Höijer, 1990). It is sufficient to claim that a large number of thoughts do occur, and that at least the most salient thoughts can indeed be reported. Nonetheless, this question as well as other problems related to various types of validity will have to be addressed in future studies. After the operationalization is complete, we can begin to assess which specific types of elements, relations, and domains are used in television news interpretation, and establish if interpretive complexity is related to viewer characteristics, content features, and social contexts.

Finally, decades of research have shown that viewers do not recall and understand much from television news, which indicates that the role of television news as an important dispenser of public affairs information should not be overestimated. Measuring recall and comprehension, while very informative is also limited, and studying interpretive complexity may help us to better understand the role television news plays in society.

\section{Acknowledgement}

The authors would like to thank Ruben Konig for his input on earlier versions of this article.

\section{Notes}

1. Depending on the scholarly tradition, this mental knowledge structure is called schema, network, cognitive map, relevance structure, or frame. We would like to emphasize that we use the term knowledge structure in a broad sense; it includes both cognitive and affective aspects.

2. Differentiation and integration are concepts from cognitive complexity theory, which has its foundations in cognitive and social psychology and has also been used in political science. In cognitive psychology, cognitive complexity is used to explain such things as (differences in) information processing and task performance (cf. Anderson and Lebiere, 1998; Ericsson and Simon, 1984; Newell and Simon, 1972; Segal and Shaw, 1988). People with a more complex cognitive structure have been found to be better equipped to process information and complete tasks. In social psychology it is used to study social perception, attitudes, and attribution, such as the in-group-out-group phenomena (cf. Linville, Fischer, and Salovey, 1989). People generally have a more differentiated image of their own social group than of other groups. In political science, the concept of 'political sophistication' refers to cognitive complexity in the domain of politics. It signifies the level of thinking about politics (cf. Luskin, 1990; Neuman, 1981; Tetlock, 1984). In addition, various analyses of archival data, such as political speeches, transcripts of policy decisions, and novels, have been conducted (e.g., Suedfeld and Tetlock, 1977). The concept is often called 'cognitive complexity' or 'integrative complexity' (cf. Suedfeld and Tetlock, 1977). In political studies, terms such as 'political sophistication', 'ideology', or 'expertise' are used (cf. Lau and Erber, 1985; Luskin, 1990; 
Neuman, 1981; Putnam, 1971). Social psychology prefers terms such as 'beliefs', 'social categories' and 'attributes' (cf. Linville, 1982; Linville et al., 1989), whereas cognitive psychologists use 'units' and 'associations'. In fact, these terms are all specific uses of (parts of) the same general concept of 'cognitive complexity' (Luskin, 1987).

3. Spradley maintains that cross-cultural studies show that the number of semantic relationships is limited; probably less than a dozen (Spradley, 1979). Moreover, they seem to be universal. Consequently, they are very fit to act as tools in our search for structural elements of the interpretation of television news.

4. Conceptualizations of integration in other disciplines vary across authors and research questions (cf. Luskin, 1987). In some studies, integration is conceptualized as an abstraction per se, and inferred from peoples' references (e. g., in interviews) to abstract concepts, or comparisons between alternative solutions to problems or perspectives on issues. The main idea behind this is that use of abstract concepts is possible only if the person doing so has made causal links and/or has grouped elements together in some form of cognitive category. In other words, integration is conceptualized using specific symptoms or inferences of integration. This conceptualization is mainly used in political studies on 'political sophistication'. People are seen as more sophisticated in political matters if they can see issues in abstract political terms such as 'liberalism vs. conservatism'. In our concept, we are not looking for a level of political sophistication. Rather, we seek a concept that, if differentiation represents the richness of an interpretation, integration represents the boundaries; i. e., the way in which this richness is organized into all kinds of abstract categories. Moreover, another problem is that ultimately analyzing abstraction requires a great amount of interpretation by the coder, and it is difficult to distinguish between concepts that are very abstract, less abstract, or not at all abstract. Consequently, coder bias is a great threat (Baker-Brown et al., 2004; Suedfeld et al., 1992). These aspects make measurement of integration in terms of levels of abstractness somewhat crude and subjective (Luskin, 1987).

5. The fact that a general consensus exists on the content and boundaries of social domains, also implies that occasional disagreements can occur. These struggles over disagreements on definitions of the situation are probably when social change eventually could occur. For us this occasional opacity means that some elements fall into more than one domain if they relate to more than one social situation.

\section{References}

Al-Menayes, J. J. and Sun, S. W. (1993). Processing complex information: What are cognitive units and how are they related? Gazette, 52, 57-84.

Anderson, J. R. and Lebiere, C. (1998). The atomic components of thought. London: Lawrence Erlbaum.

Baker-Brown, G., Ballard, E. J., Bluck, S., de Vries, B., Suedfeld, P., and Tetlock, P. E. (2004). Coding manual for conceptuallintegrative complexity. Available (consulted on December 1, 2004) at http://www.psych.ubc.ca/ psuedfeld/RESTlab/ Complexity/Workshop/MANUAL.PDF

Berger, P. L. and Luckmann, Th. (1967). The social construction of reality: A treatise in the sociology of knowledge. New York: Doubleday.

Berry, C. (1983). Learning from television news: A critique of the research. Journal of Broadcasting, 27, 359-370.

Brosius, H. B. and Berry, C. (1990). Ein drei Faktorenmodell der Wirkung von Fernsehnachrichten [A three factor model of the influence of television news]. Media Perspektiven, 9, 573-583. 
Cacioppo, J. T., Von Hippel, W., and Ernst, J. M. (1997). Mapping cognitive structures and process through verbal content: The thought-listing technique. Journal of Consulting and Clinical Psychology, 65(6), 928-940.

Carragee, K. M. and Roefs, W. (2004). The neglect of power in recent framing research. Journal of Communication, 54, 214-233.

Celsi, R. L. and Olson, L. C. (1988). The role of involvement in attention and comprehension processes. Journal of Consumer Research, 15, 210-225.

Craik, F. and Lockhart, R. (1972). Levels of processing: A framework for memory research. Journal of Verbal Learning and Verbal Behavior, 11, 671-684.

Davison, G. C., Vogel, R. S., and Coffman, S. G. (1997). Think-aloud approaches to cognitive assessment and the articulated thoughts in simulated situations paradigm. Journal of Consulting and Clinical Psychology, 65(6), 950-958.

Drew, D. and Reeves, B. (1980). Learning from a television news story. Communication Research, 7, 121-135.

Dijk, T. van (1983). Discourse analysis: Its development and implication to the structures of news. Journal of communication, 33, 20-43.

Findahl, O. (1997). Go cognitive and go on-line: New directions in media research. In U. Carlsson (Ed.), Beyond media uses and effects (pp. 61-80). Göteborg: Nordicom.

Findahl, O. (1998). News in our minds. Communications: The European Journal of Communication Research, 23, 409-425.

Findahl, O. and Höijer, B. (1985). Some characteristics of news memory and comprehension. Journal of Broadcasting and Electronic Media, 29, 379-396.

Fisher, K. (1997). Locating frames in the discursive universe. Sociological Research Online, 2(3). Available (consulted May 13, 2002) at http://www.socresonline.org. uk/socresonline/2/3/4.html

Fiske, S. T., and Taylor, S. E. (1991). Social cognition. New York: McGraw-Hill.

Früh, W. (1990). Strukturierung themenbezogenen Wissens bei Massenmedien und Publikum. In K. Böhme-Dürr, J. Emig, and N. Seel (Eds.), Wissensveränderung durch Medien? Theoretische Grundlagen und empirische Analysen (pp. 151-169). München: K. G. Saur.

Giegler, H. and Ruhrmann, G. (1990). Remembering the news: A LISREL model. European Journal of Communication, 5, 463-488.

Glasgow Media Group (1995). Glasgow Media Group reader, Vol. 1. News content, language and visuals. London: Routledge.

Goffman, E. (1974). Frame analysis: An essay on the organization of experience. Cambridge, MA: Harvard University Press.

Graber, D. A. (1984). Processing the news: How people tame the information tide. New York: Longman.

Graber, D. A. (1990). Seeing is remembering: How visuals contribute to learning from television news. Journal of Communication, 40, 134-155.

Graesser A. C., Singer, M., and Trabasso T. (1994). Constructing inferences during narrative text comprehension. Psychological Review, 101, 371-395.

Gunter, B. (1979). Recall of television news items: Effects of presentation mode, picture content, and serial position. Journal of Educational Television, 5, 57-61.

Gunter, B. (2001). Television news and the audience in Europe: What has been happening and where should we go next? In K. Renckstorf, D. McQuail, and N. Jankowski (Eds.), Television news research: Recent European approaches and findings (pp. 17-46). Berlin: Quintessenz.

Gunter, B., Furnham, A., and Gietson, G. (1984). Memory for the news as a function of the channel of communication. Human Learning, 3, 265-271. 
Guttieri, K., Wallace, M. D., and Suedfeld, P. (1995). The integrative complexity of American decision makers in the Cuban missile crisis. The Journal of Conflict Resolution, 39, 595-621.

Hendriks Vettehen, P., Hietbrink, N., and Renckstorf, K. (1996). Differences between men and women in recalling TV news. In K. Renckstorf, D. McQuail, and N. Jankowski (Eds.), Media use as social action: A European approach to audience studies (pp. 151-162). London: John Libbey.

Hinze, T., Doster, J., and Joe, V. C. (1997). The relationship of conservatism and cognitive-complexity. Personality and Individual Differences, 22, 297-298.

Höijer, B. (1989). Television-evoked thoughts and their relation to comprehension. Communication Research, 16, 179-203.

Höijer, B. (1998). Cognitive and psycho-dynamic perspectives on reception of television narration. In B. Höijer and A. Werner (Eds.), Cultural cognition: New perspectives in audience theory (pp. 73-84). Göteborg: Nordicom.

Höijer, B. and Werner, A. (Eds.).(1998). Cultural cognition: New perspectives in audience theory (pp. 73-84). Göteborg: Nordicom.

Iyengar, S. (1991). Is anyone responsible? How television frames political issues. Chicago, IL: University of Chicago Press.

Jensen, K. B. (1988). News as a social resource: A qualitative empirical study of the reception of Danish television news. European Journal of Communication, 3, $275-301$.

Jensen, K. B. (Ed.).(1998). News of the world: World cultures look at television news. London: Routledge.

Judd, C. and Krosnick, J. (1989). The structural bases of consistency among political attitudes: Effects of political expertise and attitude importance. In A. R. Pratkanis, S. J. Breckler, and A. G. Greenwald (Eds.), Attitude structure and function. Hillsdale, NJ: Lawrence Erlbaum.

Kintsch, W. (1998). Comprehension: A paradigm for cognition. Cambridge: Cambridge University Press.

Konig, R., Renckstorf, K., and Wester, F. (2001). Patterns in television news use. In K. Renckstorf, D. McQuail, J. E. Rosenbaum, and G. Schaap (Eds.), Action theories in communication research: Recent developments in Europe (pp. 253-278). Berlin: Mouton De Gruyter.

Kleinnijenhuis, J. (1990). Newspaper complexity and the knowledge gap. Paper presented at the IAMCR conference, Bled, Yugoslavia.

Kleinnijenhuis, J., Peeters, A., Hietbrink, N., and Spaans, D. (1991). Het nieuwsaanbod van NOS en RTL en wat kijkers ervan leren [The news offered by NOS and RTL and what viewers learn from it]. Massacommunicatie, 3, 197-226.

Lau, R. R. and Erber, R. (1985). Political sophistication: An information-processing perspective. In S. Kraus and R. M. Perloff (Eds.), Mass media and political thought (pp. 37-64). Beverly Hills, CA: Sage.

Lemish, D. (2001). What is news? A cross-cultural examination of kindergartners' understanding of news. In K. Renckstorf, D. McQuail and N. Jankowski (Eds.), Television news research: Recent European approaches and findings (pp. 361-374). Berlin: Quintessenz.

Levy, M. R. (1978). The audience experience with television news. Journalism Monographs, 55, 1-29.

Levy, M. R. (1983). Conceptualizing and measuring aspects of audience 'activity'. Journalism Quarterly, 60(1), 109-115.

Linville, P. W. (1982). The complexity-extremity effect and age-based stereotyping. Journal of Personality and Social Psychology, 42, 193-211. 
Linville, P. W., Fischer, G. W., and Salovey, P. (1989). Perceived distributions of the characteristics of in-group and out-group members: Empirical evidence and a computer simulation. Journal of Personality and Social Psychology, 57, 165-188.

Livingstone, S. (1990). Making sense of television: The psychology of audience interpretation. London: Routledge.

Luskin, R. C. (1987). Measuring political sophistication. American Journal of Political Science, 31, 856-899.

Luskin, R. C. (1990). Explaining political sophistication. Political Behavior, 12, $331-361$.

Molen, C. van der (1989). 'Slapen, eten, drinken, werken en het journaal': Hoe mensen in de huiselijke sfeer naar het journaal kijken ['Sleep, eat, drink, work, and the news': How people watch the news in their homes]. Massacommunicatie, 4, $322-330$.

Neuman, W. R. (1981). Differentiation and integration: Two dimensions of political thinking. American Journal of Sociology, 86, 1236-1268.

Newell, A. and Simon, H. A. (1972). Human problem solving. London: Prentice-Hall.

Parkin, A. J. (2000). Essential cognitive psychology. Hove: Psychology Press.

Petty, R. E. and Caccioppo, J. T. (1986). Communication and persuasion: Central and peripheral routes to attitude change. New York: Springer.

Price, V., Tewksbury, D., and Powers, E. (1997). Switching trains of thought. The impact of news frames on readers' cognitive responses. Communication Research, 24, 481-506.

Putnam, R. D. (1971). Studying elite culture: The case of ideology. The American Political Science Review, 65, 651-681.

Renckstorf, K. and Rohland, L. (1980). Nachrichtensendungen im Fernsehen [News broadcasts on television]. Berlin: Spieß.

Renckstorf, K. and Wester, F. (2001). An action theoretical frame of reference for the study of TV news use. In K. Renckstorf, D. McQuail, and N. Jankowski (Eds.), Television news research: Recent European approaches and findings (pp. 91-110). Berlin: Quintessenz.

Robinson, J. P. and Davis, D. K. (1990). Television news and the informed public: An information processing approach. Journal of Communication, 40, 106-119.

Robinson, J. P. and Levy, M. R. (1986). The main source: Learning from television news. Beverly Hills, CA: Sage.

Rosengren, K. E. (1986). Media linkages between culture and other societal systems. In M. McLaughlin (Ed.), Communication Yearbook 9 (pp. 19-57). Beverly Hills, CA: Sage.

Roskos-Ewoldsen, D. (2004). Mental representation of news stories. Paper presented at the ICA conference, New Orleans, LA, May 2004.

Salomon, G. (1984). Television is 'easy' and print is 'tough': The differential investment of mental effort in learning as a function of perceptions and attributions. Journal of Educational Psychology, 76, 647-658.

Satterfield, J. M. (1998). Cognitive-affective states predict military and political aggression and risk taking: A content analysis of Churchill, Hitler, Roosevelt, and Stalin. The Journal of Conflict Resolution, 42, 667-690.

Schaap, G. (2004). Using protocol analysis in television news research: Proposal and first tests. In K. Renckstorf, D., McQuail, J. E. Rosenbaum, and G. Schaap (Eds.), Action theories in communication research: Recent developments in Europe (pp. 115-140). Berlin: Mouton De Gruyter.

Schaap, G., Renckstorf, K., and Wester, F. (2001). Three decades of television news research: An action theoretical inventory of issues and problems. In K. Renckstorf, D. McQuail, and N. Jankowski (Eds.), Television news research: Recent European approaches and findings (pp. 47-90). Berlin: Quintessenz. 
Schroder, H. M., Driver, M. J., and Streufert, S. (1967). Human information processing: Individuals and groups functioning in complex social situations. New York: Holt, Rinehart and Winston.

Scott, W. A. (1963). Cognitive complexity and cognitive balance. Sociometry, 26(1), $66-74$.

Segal, Z. V. and Shaw, B. F. (1988). Cognitive assessment: Issues and methods. In K. S. Dobson (Ed.), Handbook of cognitive-behavioral therapies (pp. 39-81). New York: Guilford.

Shapiro, M. A. and Lang, A. (1991). Making television reality: Unconscious processes in the construction of social reality. Communication Research, 18, 685-705.

Shah, D., Kwak, N., Schmierbach, M., and Zubric, J. (2004). The interplay of news frames on cognitive complexity. Human Communication Research, 30, 102-120.

Sigall, H. and Johnson, M. B. (1998). The relationship between political preference and judgments of president Clinton's integrity depends on cognitive complexity. Journal of Applied Social Psychology, 28, 1465-1476.

Spradley, J. P. and McCurdy, D. W. (1972). The cultural experience: Ethnography in complex society. Chicago, IL: Science Research.

Spradley, J. P. (Ed.). (1972). Culture and cognition: Rules, maps, and plans. San Francisco, CA: Chandler.

Spradley, J. P. (1979). The ethnographic interview. New York: Holt, Rinehart and Winston.

Spradley, J. P. (1980). Participant observation. New York: Holt, Rinehart and Winston.

Suedfeld, P. and Leighton, D. C. (2002). Early communications in the war against terrorism: An integrative complexity analysis. Political Psychology, 23, 585-600.

Suedfeld, P. and Tetlock, P. E. (1977). Integrative complexity of communications in international crises. The Journal of Conflict Resolution, 21(1), 169-184.

Suedfeld, P., Tetlock, P. E., and Streufert, S. (1992). Conceptual/integrative complexity: The development and current state of the construct. In C. P. Smith (Ed.), Motivation and personality: Handbook of thematic content analysis (pp. 393-400). New York: Cambridge University Press.

Tajfel, H. (1981). Human groups and social categories: Studies in social psychology. Cambridge, MA: Cambridge University Press.

Tetlock, P. E. (1984). Cognitive style and political belief systems in the British House of Commons. Journal of Personality and Social Psychology, 46, 365-375.

Vitouch, P. and Tichon, H. J. (Eds.).(1996). Cognitive maps und medien: Formen mentaler Repräsentation bei der medienwahrnehmung [Cognitive maps and media: Forms of mental representation in media perception]. Frankfurt am Main: Peter Lang.

Wahldahl, R. (1998). A cognitive perspective on media effects. In B. Höijer and A. Werner (Eds.), Cultural cognition: New perspectives in audience theory (pp. 4158). Göteborg: Nordicom.

Walma van der Molen, J. H. and Van der Voort, T. H. A. (1997). Children's recall of television and print news: A media comparison study. Journal of Educational Psychology, 89(1), 82-91.

Woodall, W. G., Davis, D. K., and Sahin, H. (1983). From the boob tube to the black box: Television news comprehension from an information processing perspective. Journal of Broadcasting, 27(1), 1-23.

Zajonc, R. B. (1968). Cognitive theories in social psychology. In G. Lindzey and E. Aronson (Eds.), The handbook of social psychology, volume I (2nd ed., pp. 320411). Reading, MA: Addison-Wesley. 